$06.1 ; 06.5$

\title{
Деформация элементарной ячейки при прерывистом напылении пленок ниобата бария-стронция
}

\author{
(ㄱ Д.В. Стрюков ${ }^{1}$, А.В. Павленко ${ }^{1,2}$ \\ ${ }^{1}$ Федеральный исследовательский центр Южный научный центр РАН, Ростов-на-Дону, Россия \\ 2 Южный федеральный университет, Ростов-на-Дону, Россия \\ E-mail: strdl@mail.ru
}

Поступило в Редакцию 18 июля 2019г.

В окончательной редакции 18 июля 2019г.

Принято к публикации 26 августа 2019г.

\begin{abstract}
Методом высокочастотного катодного распыления с применением технологии прерывистого напыления изготовлены эпитаксиальные тонкие пленки $\mathrm{Sr}_{0.5} \mathrm{Ba}_{0.5} \mathrm{Nb}_{2} \mathrm{O}_{6} / \mathrm{MgO}$ с различной толщиной слоев, но с одинаковой общей толщиной. Установлено, что уменьшение толщины слоя приводит к увеличению деформации элементарной ячейки, которая сохраняется, если толщина последующих слоев не превышает критическую.
\end{abstract}

Ключевые слова: сегнетоэлектрики, прерывистое напыление, деформации элементарной ячейки.

DOI: 10.21883/PJTF.2019.23.48714.17988

С развитием технологий напыления тонких эпитаксиальных пленок (импульсное лазерное напыление, молекулярно-лучевая эпитаксия, высокочастотное катодное распыление [1]) появилась возможность создавать в материале значительные деформации элементарной ячейки за счет осаждения пленок на соответствующие монокристаллические подложки $\left(\mathrm{Si}, \mathrm{MgO}, \mathrm{Al}_{2} \mathrm{O}_{3}, \mathrm{SrTiO}_{3}\right.$ и др.), что повлекло за собой выделение деформационной инженерии в отдельное направление исследований в современной физике наноструктур. Она предоставляет возможность кардинально менять свойства материала без изменения его состава [2,3]. С этой точки зрения крайне актуальным является исследование сегнетоэлектрических материалов, которые привлекают огромное внимание в связи с потребностью в создании новых типов памяти, пьезоэлектрических датчиков, микроактюаторов, электрооптических модуляторов и др. [1,4]. Ниобат бария-стронция, $\mathrm{Sr}_{x} \mathrm{Ba}_{1-x} \mathrm{Nb}_{2} \mathrm{O}_{6}(\mathrm{SBN})$, является одноосным сегнетоэлектриком-релаксором, проявляющим высокие значения пироэлектрического и электрооптического коэффициентов, что делает его одним из кандидатов для создания СВЧ-модуляторов, пироэлектрических инфракрасных детекторов и устройств интегральной оптики $[5,6]$. SBN имеет структуру незаполненной тетрагональной вольфрамовой бронзы. Элементарная ячейка состоит из кислородных октаэдров $\mathrm{NbO}_{6}$, образующих треугольные, четырехугольные и пятиугольные каналы. Атомы Sr занимают четырех- и пятиугольные каналы, a атомы Ва занимают только пятиугольные каналы, треугольные каналы остаются незанятыми. При этом некоторые из четырех- и пятиугольных каналов также остаются незаполненными [7].

В настоящей работе получены и исследованы пленки $\mathrm{Sr}_{0.5} \mathrm{Ba}_{0.5} \mathrm{Nb}_{2} \mathrm{O}_{6}(\mathrm{SBN}-50) / \mathrm{MgO}$ с одинаковой общей толщиной, но с различной толщиной слоев. Изучено влияние уменьшения толщины слоя на возникающие деформации элементарной ячейки, а также возможность сохранения деформации с увеличением толщины слоев.

Пленки SBN-50 были выращены на подложках $\mathrm{MgO}(001)$ методом высокочастотного катодного распыления керамической мишени соответствующего стехиометрического состава. Технология получения была описана нами ранее [8]. Скорость роста составляла $5 \mathrm{~nm} / \mathrm{min}$. Была использована технология прерывистого напыления для последовательного напыления нескольких слоев одного материала, когда после напыления очередного слоя образец полностью остывал и в камеру напускалась атмосфера. Были получены пленки SBN-50/MgO с различными толщинами слоев: $25+25 \mathrm{~nm}, \quad 10+10+10+10+10 \mathrm{~nm}(10 \times 5 \mathrm{~nm})$ и $10+40 \mathrm{~nm}$. Перед напылением каждого последующего слоя проводился рентгенодифракционный анализ с использованием модернизированного дифрактометра ДРОН-4-07 ( $\mathrm{Cu} K_{\alpha}$-излучение).

По результатам рентгенодифракционного анализа установлено, что во всех пленках отсутствуют примесные фазы (рис. 1, $a$ ), на рентгенограммах присутствуют только рефлексы $(00 l)$ пленки и подложки. Вертикальная разориентировка пленок, определенная по полуширине кривой качания, не превышала $2.6^{\circ}$ (вставка на рис. $\left.1, a\right)$. Эпитаксиальный рост пленок доказан $\varphi$-сканированием отражения (311) пленки (рис. $1, b$ ), где присутствует 12 максимумов, что соответствует формированию двух типов ориентационных доменов. Аналогичная ситуация уже наблюдалась нами ранее в тонких пленках без использования технологии прерывистого напыления [9]. Угловые положения максимумов при $\varphi$-сканировании рефлексов (311) пленки и (113) подложки соответствуют развороту кристаллографических осей пленки относительно осей подложки в плоскости сопряжения на углы $\pm 18.4^{\circ}$, что также соответствует пленкам без использования прерывистого напыления [9]. 

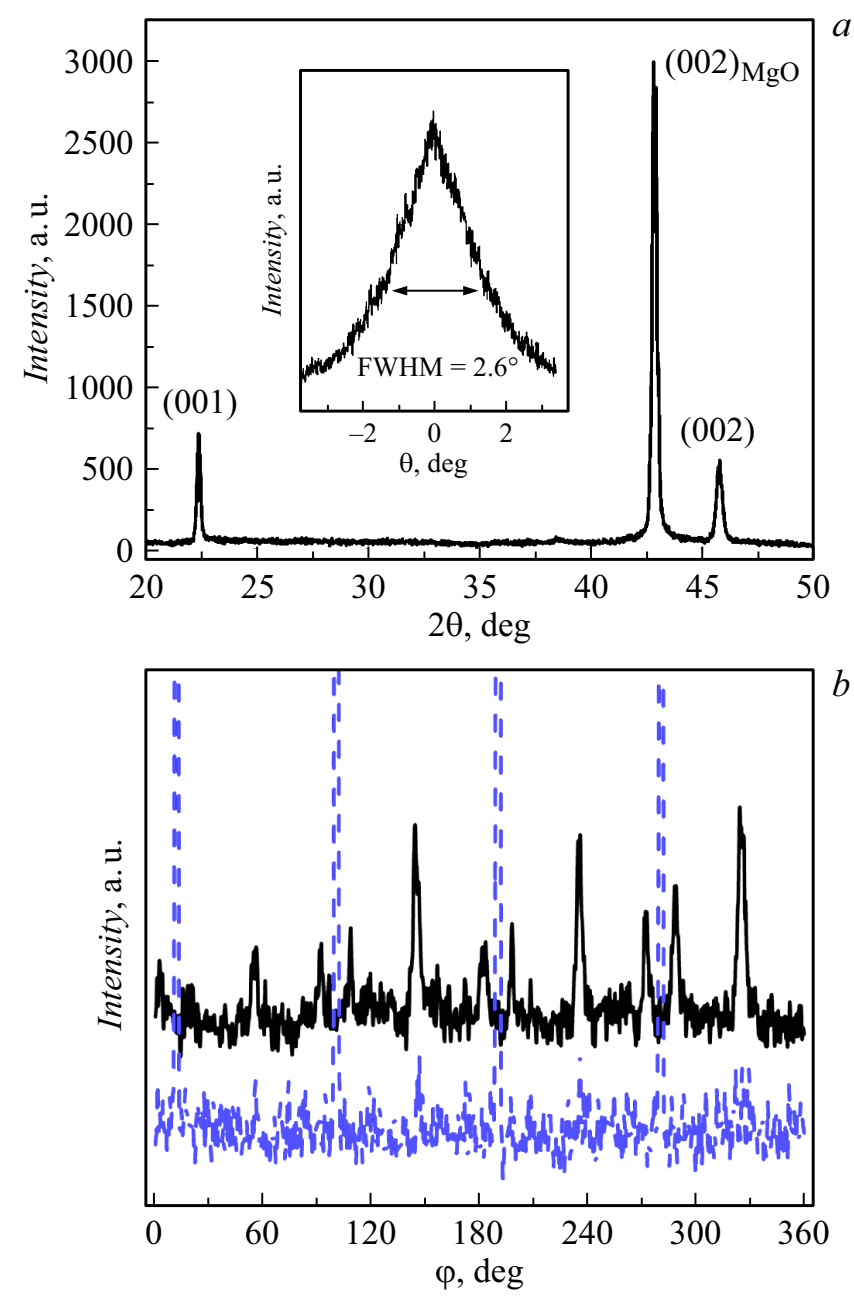

Рис. 1. $a-\theta-2 \theta$-рентгенограмма пленки $\mathrm{SBN}-50 / \mathrm{MgO}$ толщиной $10 \times 5 \mathrm{~nm}$; на вставке - кривая качания отражения (002). $b-\varphi$-сканирование рефлексов (311) пленки (сплошная линия) и (113) подложки (штриховая линия).

При сравнении угловых положений рефлексов пленки толщиной $10 \times 5 \mathrm{~nm}$ и пленки толщиной $25+25 \mathrm{~nm}$ (рис. 2) видно, что уменьшение толщины слоев дало существенный сдвиг. По полученным данным определены параметры элементарной ячейки $c_{10 \times 5}=0.3969(1) \mathrm{nm}$ и $c_{25+25}=0.3961(1) \mathrm{nm}$. Величина изменения параметра элементарной ячейки за счет уменьшения толщины слоя сравнима с аналогичной величиной за счет влияния допирования SBN-50 4\% Gd [10]. Сравнивая полученные параметры элементарных ячеек с параметрами для объемного материала $\left(a_{b u l k}=1.2472 \mathrm{~nm}\right.$, $\left.c_{\text {bulk }}=0.3940 \mathrm{~nm}\right)$, можно рассчитать деформацию элементарной ячейки $\varepsilon_{10 \times 5}=\left(c_{\text {film }}-c_{\text {bulk }}\right) / c_{\text {bulk }}=0.007$, а $\varepsilon_{25+25}=0.005$. Таким образом, дополнительная деформация элементарной ячейки за счет уменьшения толщины слоя составила $\Delta \varepsilon=0.002$, т. е. увеличилась на треть.

При прерывистом напылении слоев одного состава по сути происходит увеличение общей толщины пленки, что приводит к увеличению интенсивности дифракционного отражения. Так, при каждом напылении слоя в
$10 \mathrm{~nm}$ проводилась съемка отражений (001) и (002) пленки (рис. 3). Видно, что с добавлением каждого последующего слоя интенсивность монотонно растет без сдвига в угловых положениях. Однако при напылении поверх $10 \mathrm{~nm}$ слоя толщиной $40 \mathrm{~nm}$ помимо ожидаемого роста интенсивности происходит также релаксация дополнительной деформации. Это проявляется в сдвиге угловых положений рефлексов (рис. 2) назад в положение, характерное для пленки $25+25 \mathrm{~nm}$. И в этом случае параметры элементарных ячеек пленок толщиной $25+25$ и $10+40 \mathrm{~nm}$ равны: $c_{10+40}=c_{25+25}=0.3961(1) \mathrm{nm}$.

Таким образом, методом прерывистого напыления были получены эпитаксиальные тонкие пленки $\mathrm{SBN}-50 / \mathrm{MgO}$. В них аналогично однослойным пленкам без использования прерывистого напыления формируется только два типа ориентационных доменов, оси которых повернуты относительно осей подложки на $\pm 18.4^{\circ}$.

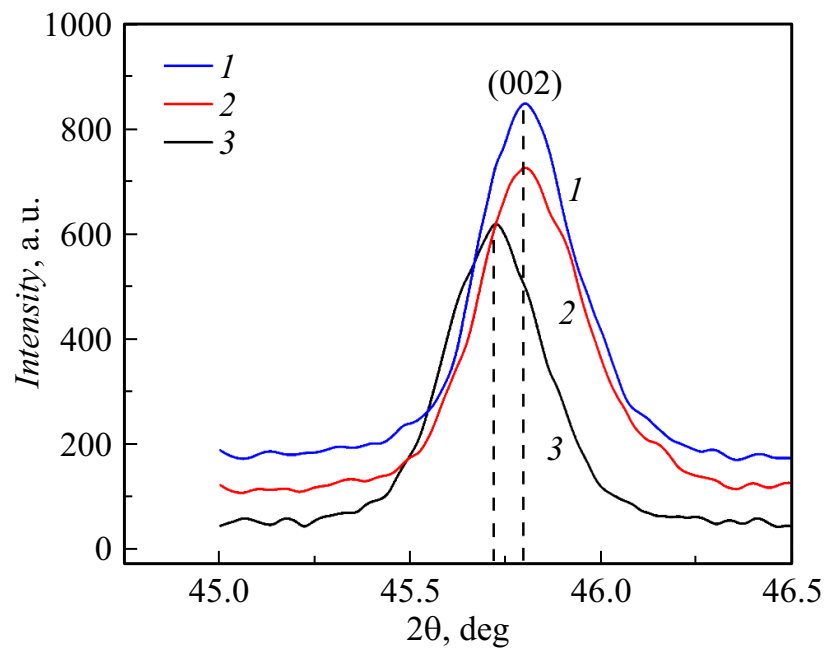

Рис. 2. Прецизионная $\theta-2 \theta$-съемка рефлекса (002) пленок $\mathrm{SBN}-50 / \mathrm{MgO}$ толщиной $25+25(1), 10+40(2)$ и $10 \times 5 \mathrm{~nm}$ (3).

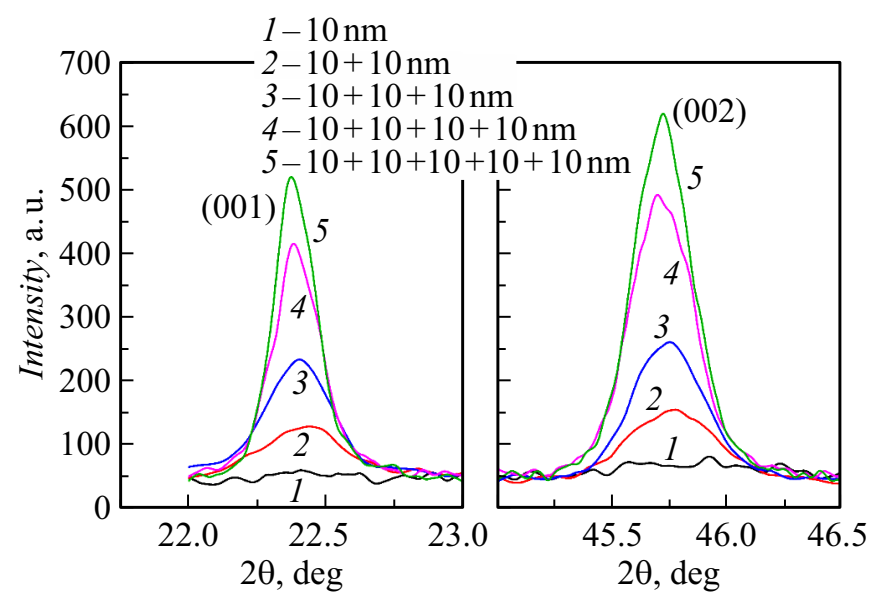

Рис. 3. Прецизионная $\theta-2 \theta$-съемка рефлексов (001) и (002) пленки SBN-50/MgO при последовательном напылении слоев толщиной $10 \mathrm{~nm}(10 \times 5 \mathrm{~nm})$. 
B SBN-50 по сравнению с материалами со структурой перовскита $\left(\mathrm{Ba}_{x} \mathrm{Sr}_{1-x} \mathrm{TiO}_{3}\right.$ [1], $\mathrm{PbZr}_{1-x} \mathrm{Ti}_{x} \mathrm{O}_{3}$ [3] и др.) удается достичь лишь очень маленьких величин деформации элементарной ячейки. По-видимому, это связано с наличием незанятых $A$-позиций в элементарной ячейке, что позволяет структуре подстраиваться под внешнее воздействие. Например, при значительном изменении температуры от 150 до $400 \mathrm{~K}$ изменение параметра $c$ не превышает $0.0005 \mathrm{~nm}$ [11]. При напылении SBN-50 в виде тонкой пленки удается достичь значительных для структуры ниобата бария-стронция деформаций элементарной ячейки. А уменьшение толщины слоя до $10 \mathrm{~nm}$ позволяет усилить деформации элементарной ячейки еще на треть. Получение толстых пленок с увеличенной деформацией с использованием технологии прерывистого напыления возможно, однако толщина каждого слоя не должна превышать критическую (толщина первого слоя). Опираясь на полученные нами ранее результаты исследования тонких пленок SBN-50 [12], можно ожидать значительных изменений их оптических и электрофизических свойств из-за существенного увеличения деформации элементарной ячейки. На исследование этих изменений и будет направлена наша дальнейшая работа.

\section{Финансирование работы}

Работа выполнена в рамках государственного задания ЮНЦ РАН по проекту № 0120-1354-247, а также при поддержке гранта Президента РФ № МК-4100.2018.2.

\section{Конфликт интересов}

Авторы заявляют, что у них нет конфликта интересов.

\section{Список литературы}

[1] Мухортов В.М., Юзюк Ю.И. Гетероструктуры на основе наноразмерных сегнетоэлектрических пленок: получение, свойства и применение. Ростов н/Д: Изд-во ЮНЦ РАН, 2008. $224 \mathrm{c}$.

[2] Schlom D.G., Chen L.-Q., Fennie C.J., Gopalan V., Muller D.A., Pan X., Ramesh R., Uecker R. // MRS Bull. 2014. V. 39. N 2. P. $118-130$. DOI: $10.1557 / \mathrm{mrs} .2014 .1$

[3] Janolin P.-E. // J. Mater. Sci. 2009. V. 44. N 19. P. 5025-5048. DOI: $10.1007 / \mathrm{s} 10853-009-3553-1$

[4] Бирюков С.В., Головко Ю.И., Масычев С.И., Мухортов В.M. // Наука юга России. 2016. Т. 12. № 1. С. 11-15.

[5] Kulkarni A.R., Patro P.K. // Trans. Indian Ceram. Soc. 2010. V. 69. N 3. P. $135-146$. DOI: 10.1080/0371750x.2010.11090830

[6] Gupta S., Paliwal A., Gupta V., Tomar M. // Appl. Surf. Sci. 2018. V. 458. P. 139-144. DOI: 10.1016/j.apsusc.2018.07.039

[7] Кузьминов Ю.С. Сегнетоэлектрические кристаллы для управления лазерным излучением. М.: Наука, 1982. 400 с.

[8] Толмачев Г.Н., Ковтун А.П., Захарченко И.Н., Алиев И.М., Павленко А.В., Резниченко Л.А., Вербенко И.А. // ФТТ. 2015. T. 57. B. 10. C. 2050-2055.
[9] Широков В.Б., Павленко А.В., Стрюков Д.В., Ревинский Ю.В. // ФТТ. 2018. Т. 60. В. 5. С. 993-998. DOI: 10.21883 /FTT.2018.05.45801.228

[10] Lam K.K., Chan K.H., Ng S.M., Wong H.F., Liu Y.K., Leung C.W., Mak C.L. // Phys. Status Solidi A. 2018. V. 216. N 8. P. 1800660 . DOI: $10.1002 /$ pssa.201800660

[11] Podlozhenov S., Graetsch H.A., Schneider J., Ulex M., Whilecke M., Betzler K. // Acta Cryst. B. 2006. V. 62. P. 960 965. DOI: $10.1107 / \mathrm{s} 0108768106038869$

[12] Павленко А.В., Ковтун А.П., Зинченко С.П., Стрюков Д.В. // Письма в ЖТФ. 2018. Т. 44. В. 11. С. 30-37. DOI: 10.21883/PJTF.2018.11.46194.17257 